\title{
Plasmodium vivax hypoxanthine-guanine phosphoribosyltransferase: A target for anti-malarial chemotherapy
}

\author{
Dianne T. Keough a ${ }^{\text {, Dana Hockováb }}{ }^{\text {, Marcela Krečmerováb }}{ }^{\text {, Michal Česnek }}{ }^{\mathrm{b}}$, Antonín Holý ${ }^{\mathrm{b}}$, \\ Lieve Naesens $^{\mathrm{c}}$, Ian M. Brereton ${ }^{\mathrm{d}}$, Donald J. Winzor ${ }^{\mathrm{a}}$, John de Jersey ${ }^{\mathrm{a}}$, Luke W. Guddat ${ }^{\mathrm{a}, *}$ \\ a The School of Chemistry and Molecular Biosciences, The University of Queensland, Brisbane, 4072, QLD, Australia \\ ${ }^{\mathrm{b}}$ Institute of Organic Chemistry and Biochemistry, Academy of Sciences of the Czech Republic, v.v.i. Flemingovo nam. 2, CZ-166 10 Prague 6, Czech Republic \\ ${ }^{\mathrm{c}}$ Rega Institute for Medical Research, Katholieke Universiteit Leuven, Minderbroedersstraat 10, B-3000, Leuven, Belgium \\ ${ }^{\mathrm{d}}$ Centre for Advanced Imaging, The University of Queensland, Brisbane, 4072, QLD, Australia
}

\section{A R T I C L E I N F O}

\section{Article history:}

Received 12 January 2010

Received in revised form 25 May 2010

Accepted 25 May 2010

Available online 1 June 2010

\section{Keywords:}

Plasmodium vivax

Purine salvage pathway

6-Oxopurine phosphoribosyltransferase

Acyclic nucleoside phosphonates

\begin{abstract}
A B S T R A C T
The malarial parasite, Plasmodium vivax $(P v)$, causes a serious infectious disease found primarily in Asia and the Americas. For protozoan parasites, 6-oxopurine phosphoribosyltransferases (PRTases) provide the only metabolic pathway to synthesize the purine nucleoside monophosphates essential for DNA/RNA production. We have purified the recombinant $P v 6$-oxopurine (PRTase) and compared its properties with the human and $P f$ enzymes. The $P v$ enzyme uses hypoxanthine and guanine with similar catalytic efficiency to the $P f$ enzyme but xanthine is not a substrate, hence we identify this enzyme as $P v$ HGPRT. Mass spectrometry suggests that $P v$ HGPRT contains bound magnesium ions that are removed by EDTA resulting in loss of activity. However, the addition of $\mathrm{Mg}^{2+}$ restores activity. Acyclic nucleoside phosphonates (ANPs) are good inhibitors of PvHGPRT having $K_{\mathrm{i}}$ values as low as $3 \mu \mathrm{M}$. These compounds can form the basis for the design of new drugs aimed at combating malaria caused by $P v$.
\end{abstract}

(C) 2010 Elsevier B.V. All rights reserved.
Malaria caused by the parasite Plasmodium vivax $(P v)$ is often referred to as a neglected disease. This is because the primary focus for prevention and treatment has been directed towards Plasmodium falciparum ( $P f$ ) malaria. However, there are $\sim 2.6$ billion people living in areas of risk from attack by $P v$ and it is estimated that this species is responsible for $25-40 \%$ of the reported 515 million malarial infections each year [1]. $P v$ is the main cause of malaria outside Africa, occurring mainly in Asia (the cause of $80 \%$ of malaria infections) and the Americas (70\%) [2]. Protozoan parasites lack the enzymes to synthesize the purine nucleoside monophosphates essential for DNA/RNA production from small molecules (the de novo pathway) [3]. Thus, they rely on the salvage of hypoxanthine, guanine and possibly xanthine by 6-oxopurine phosphoribosyltransferase (PRTase) for survival and reproduction, making this enzyme an excellent target for drug design. The reactions catalysed by this enzyme are shown in Table $1 \mathrm{~A}$. The presence of divalent

Abbreviations: PRTase, phosphoribosyltransferase; PvHGPRT, Plasmodium vivax hypoxanthine-guanine-phosphoribosyltransferase; PfHGXPRT, Plasmodium falciparum hypoxanthine-guanine-xanthine phosphoribosyltransferase; HGPRT, hypoxanthine-guanine phosphoribosyltransferase; PRib-PP, 5-phospho$\alpha$-D-ribosyl-1-pyrophosphate; ANP, acyclic nucleoside phosphonate; DTT, dithiothreitol; $\mathrm{PP}_{\mathrm{i}}$, pyrophosphate.

* Corresponding author. Tel.: +61 73365 3549; fax: +61 733654699.

E-mail address: luke.guddat@uq.edu.au (L.W. Guddat). metal ions, usually $\mathrm{Mg}^{2+}$ in vivo, is required for the reaction to proceed. There are two mechanisms whereby the catalytic properties of this enzyme can be utilized for effective drug design. One mechanism is through the design of purine base analogs that, after conversion to the products of the reaction, are toxic to the cell [4]. It is proposed that their mode of action is to interfere with DNA/RNA synthesis in the parasite, in a similar manner to the anticancer agent, 6-mercaptopurine [5]. Purine bases, like guanine and hypoxanthine and their analogs, should be transported across the parasite's cell membrane either actively or passively [6-8]. Another mechanism that can be exploited for drug design is direct inhibition of the enzyme. To date, the only known inhibitors of the Pf enzyme are the immucillin 5'-phosphates [9] and the acyclic nucleoside phosphonates (ANPs) [10]. The ANPs are excellent therapeutic leads because they have a stable phosphorus-carbon bond, favourable pharmacokinetic properties and low cytotoxicity [11]. The complete genome of $P v$ has been sequenced and the gene coding for $P v$ 6-oxopurine PRTase identified [12]. To date, this enzyme has not previously been investigated or its properties examined as a potential target for chemotherapy. Here, the expression, purification and characterization of recombinant $P v$ 6-oxopurine PRTase are reported and the biochemical properties of this enzyme compared with those of the human and $P f$ 6-oxopurine PRTases. We later show this enzyme uses guanine and hypoxanthine as purine bases, but not xanthine and henceforth refer to it as PvHGPRT. New 
Table 1

(A) The reaction catalysed by the 6-oxopurine PRTases and (B) the kinetic constants of PvHGPRT for its naturally occurring substrates and purine base analogs.

A<smiles>[R]c1nc2nc[nH]c2c(=O)[nH]1</smiles><smiles>O=P([O-])([O-])OC[C@H]1O[C@@H](OP(=O)([O-])OP(=O)([O-])[O-])[C@H](O)[C@H]1O</smiles>

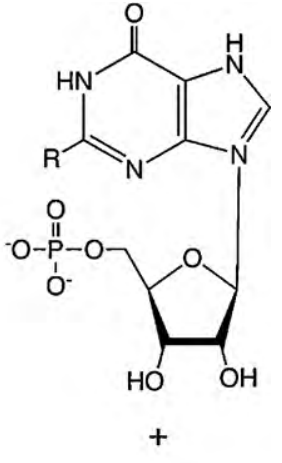

$\mathrm{PP}_{\mathrm{i}}$

\begin{tabular}{lccl}
\hline Substrate $^{\mathrm{a}}$ & \multicolumn{1}{c}{$\boldsymbol{k}_{\text {cat }}\left(\mathrm{s}^{-1}\right)$} & $K_{\mathrm{m}(\mathrm{app})}(\mu \mathrm{M})$ & $k_{\text {cat }} / K_{\mathrm{m}}\left(\mathrm{s}^{-1} \mu \mathrm{M}^{-1}\right)$ \\
\hline Hypoxanthine & $0.74 \pm 0.01$ & $0.93 \pm 0.12$ & 0.8 \\
Guanine & $1.7 \pm 0.03$ & $1.9 \pm 0.4$ & 0.9 \\
6-Mercaptopurine & $0.63 \pm 0.08$ & $1.18 \pm 0.5$ & 0.5 \\
6-Thioguanine & $1.2 \pm 0.06$ & $0.86 \pm 0.25$ & 1.4 \\
8-Azahypoxanthine & $1.1 \pm 0.13$ & $361 \pm 75$ & 0.003 \\
8-Azaguanine & $0.4 \pm 0.04$ & $110.8 \pm 20.5$ & 0.004 \\
\hline
\end{tabular}

(A) The reaction catalysed by the 6-oxopurine phosphoribosyltransferases. The naturally occurring purine bases are guanine $\left(\mathrm{R}\right.$ is $\left.-\mathrm{NH}_{2}\right)$, hypoxanthine $(\mathrm{R}$ is $-\mathrm{H})$ and xanthine ( $\mathrm{R}$ is $=\mathrm{O})$. For the $P v$ and human enzymes only guanine and hypoxanthine are substrates. For the $P f$ enzyme all three naturally occurring purine bases are substrates. (B) ${ }^{a}$ The $K_{\mathrm{m}(\mathrm{app})}$ values for these bases were measured under saturating conditions of $P$ Rib- $P P(900 \mu \mathrm{M})$. The purine base concentration ranged from $0.5 \mu \mathrm{M}$ to $60 \mu \mathrm{M}$ except for 8-azahypoxanthine (75-329 $\mu \mathrm{M})$ and 8-azaguanine (20-148 $\mu \mathrm{M})$. Seven different concentrations of the purine base were used. The statistical analysis for the $K_{\mathrm{m}}$ and $V_{\max }$ values was calculated using Prism4 (Graphpad Software, Inc., La Jolla, CA)

ANP inhibitors of the $P v$ enzyme are identified as leads for the development of drugs to treat malaria due to infection by $P$. vivax.

Recombinant $P v$ 6-oxopurine PRTase was expressed with an $\mathrm{N}$-terminal hexa-histidine tag and purified to homogeneity as assessed by SDS-PAGE and mass spectrometry (Fig. 1). Mass spectrometry of the purified sample gave a major peak at $27,849 \mathrm{Da}$ (Fig. 1b) and a smaller peak at $27,793 \mathrm{Da}$ ( $8 \%$ of the total sig-

nal), a difference of $56 \mathrm{Da}$. The calculated mass of the monomeric polypeptide chain plus the hexa-histidine tag and the N-terminal methionine is $27,792.9 \mathrm{Da}$ which corresponds to the smaller mass in Fig. 1b. Sequencing of the purified recombinant PvHGPRT confirmed that the $\mathrm{N}$-terminal methionine had not been cleaved, the $\mathrm{N}$-terminal sequence being MHHHHHH. Thus, the smaller mass obtained in Fig. 1c is due solely to the intact polypeptide chain containing the six histidine residues and the N-terminal methionine residue. $P v$ HGPRT was initially purified using a cobalt affinity resin. The mass of that preparation of enzyme was 27,849 Da. Thus, the difference in mass units compared with the single polypeptide chain was $56.1 \mathrm{Da}$ and was tentatively attributed to the presence of one cobalt ion (mass $=58.9 \mathrm{Da}$ ). However, atomic absorption spectroscopy showed no cobalt in this preparation. Alternatively, this mass difference can be attributed to the mass of one magnesium ion (24.3 Da) and two coordinated hydroxyl ions or water molecules (total of 58 or $60 \mathrm{Da}$ ). Escherichia coli XGPRT and HPRT both contain magnesium ions in their crystal structures in the absence of the mononucleotide $[13,14]$. Thus, one possible explanation is that unliganded $P v$ HGPRT also contains bound magnesium ions. All three enzymes are purified in buffers containing $0.01 \mathrm{M} \mathrm{MgCl}_{2}$. In $E$. coli XGPRT, $\mathrm{a} \mathrm{Mg}^{2+}$ is bound to the $\mathrm{O} \delta 1$ atom of $\mathrm{E} 89$ whereas, in E. coli HPRT, it is liganded to the enzyme through two side chains that, in the amino acid sequence alignment, correspond to E145 and D146 in PvHGPRT. The crystal structure of unliganded $E$. coli HPRT shows a $\mathrm{Mg}^{2+}$ coordinated to three water molecules [14]. These two amino acids ( $E$ and $D$ ) are located in one of the most highly conserved regions in the 6-oxopurine PRTases. The free human HPRT structure does not contain $\mathrm{Mg}^{2+}$ [15] and PfHGXPRT is purified in the absence of added divalent ions, requiring only $P R i b-P P$ and hypoxanthine for stability [16]. Thus, these two enzymes do not contain $\mathrm{Mg}^{2+}$ bound to the free structure and do not need these divalent metal ions to maintain activity. PvHGPRT was dialysed into buffer containing EDTA at $5{ }^{\circ} \mathrm{C}$ overnight. This resulted in a decrease in the specific activity from 5.4 to $0.17 \mu \mathrm{mol} \mathrm{min}^{-1} \mathrm{~A}_{280^{-1}}$ and a decrease in mass by $56 \mathrm{Da}$ (Fig. 1c). The mass spectrum after dialysis shows the major component at 27,793 Da and a smaller peak at 27,849 Da ( $8 \%$ of the total) which was the major component prior to dialysis (Fig. 1b). The presence of the larger peak probably explains the small amount of active enzyme (3\%) that remains after dialysis. These results support the hypothesis that the mass difference
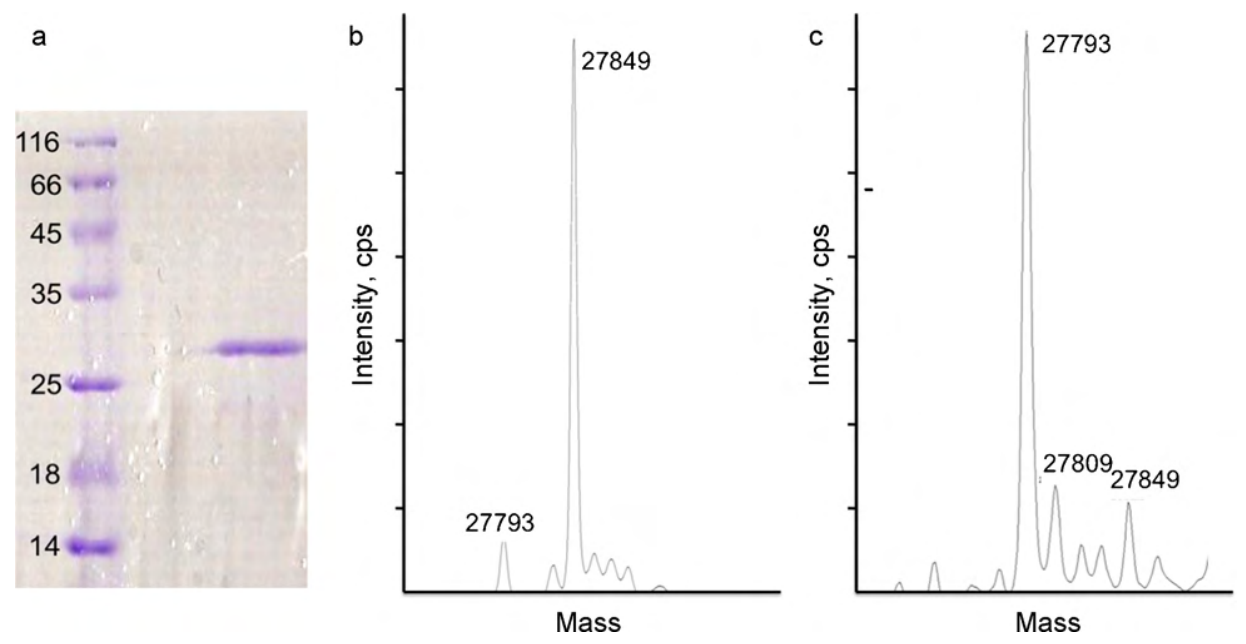

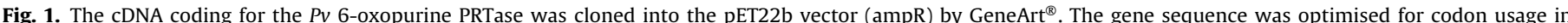

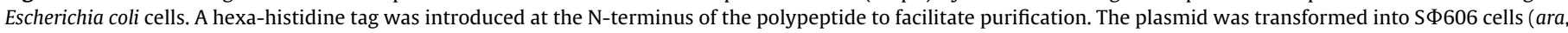

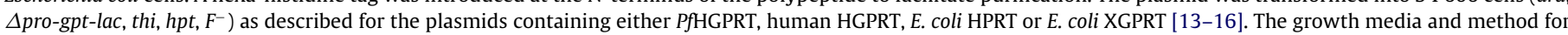

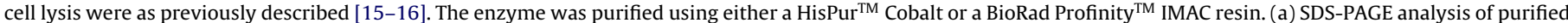

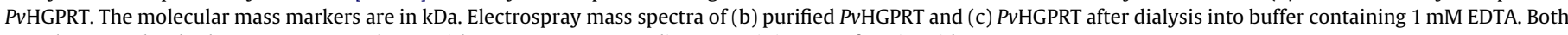
samples were desalted on a $\mathrm{C} 18$ HPLC column with a $0-60 \% \mathrm{CH}_{3} \mathrm{CN}$ gradient containing $0.1 \%$ formic acid. 
of $56 \mathrm{Da}$ is due to the presence of a metal ion, which could be attributed to one bound $\mathrm{Mg}^{2+}$ ion per monomer and accompanying water molecules or hydroxyl ions.

A sample of PvHGPRT with a specific activity of $5.2 \mu \mathrm{mol} \mathrm{min}^{-1} \mathrm{~A}_{280}{ }^{-1}$ was dialysed into buffer containing $1 \mathrm{mM}$ EDTA overnight. The specific activity decreased to $0.7 \mu \mathrm{mol} \mathrm{min}{ }^{-1} \mathrm{~A}_{280}{ }^{-1}$. The addition of buffer containing $\mathrm{MgCl}_{2}$ to give a final concentration of $\mathrm{Mg}^{2+}$ of $9 \mathrm{mM}$ resulted in an increase of activity to $2.7 \mu \mathrm{mol} \mathrm{min}{ }^{-1} \mathrm{~A}_{280^{-1}}$ after $2 \mathrm{~h}$. The addition of the same concentration of magnesium ions together with $1.8 \mathrm{mM}$ $P R i b-P P$ resulted in an increase of activity to $5.8 \mu \mathrm{mol} \mathrm{min}^{-1} \mathrm{~A}_{280^{-1}}$ in the same time period. This supports the proposition that the metal ion bound to the free enzyme is $\mathrm{Mg}^{2+}$. The loss of activity which occurred when the metal ion was removed also suggests that its presence is essential to maintain the active site structure of the enzyme; and that, after removal of $\mathrm{Mg}^{2+}$, the addition of $\mathrm{Mg}^{2+}$ or the $\mathrm{Mg}^{2+}$. PRib-PP complex restores the enzymatic activity.

The molecular mass calculated from the sedimentation equilibrium data, using a method described previously [16], is $114,000 \pm 2000$ Da which agrees well with the expected mass of $\sim 111,392$ Da for a tetramer with 27,848 Da subunits. Human and Pf enzymes also exist as tetramers in solution [15,16]. Dialysis of PvHGPRT into $\mathrm{Mg}^{2+}$-free buffer (0.1 M Tris-HCl, 1 mM DTT, pH 7.4) resulted in a loss of $90 \%$ of the activity. Ultracentrifugation showed that the enzyme still existed as a tetramer and, therefore, the loss of activity which occurs on dialysis into magnesium-free buffer is not due to dissociation of the tetrameric unit.

PvHGPRT has a specific activity for guanine of $5.2 \mu \mathrm{mol} \mathrm{min}^{-1} \mathrm{mg}^{-1}$ of protein and for hypoxanthine, $2.1 \mu \mathrm{mol} \mathrm{min}-1 \mathrm{mg}^{-1}$ of protein. Thus, in terms of $k_{\text {cat }}$, guanine is the preferred base. This difference may be due to variations in the orientation of the two substrates in the active site. The specific activities for the enzyme from $P$. falciparum are slightly lower, $1.5 \mu \mathrm{mol} \mathrm{min}^{-1} \mathrm{mg}^{-1}$ of protein using guanine and $0.77 \mu \mathrm{mol} \mathrm{min}{ }^{-1} \mathrm{mg}^{-1}$ of protein with hypoxanthine [16]. In contrast, the specific activities for the human counterpart are much higher with values of $34 \mu \mathrm{mol} \mathrm{min}^{-1} \mathrm{mg}^{-1}$ of protein for guanine and $19 \mu \mathrm{mol} \mathrm{min}{ }^{-1} \mathrm{mg}^{-1}$ of protein for hypoxanthine [16]. Lower specific activities for the naturally-occurring purine bases compared with the human enzyme are also found for the corresponding PRTases from other protozoan parasites. For example, S. mansoni HGPRT has a specific activity of $7.6 \mu \mathrm{mol} \mathrm{min}^{-1} \mathrm{mg}^{-1}$ of protein for guanine and $5.3 \mu \mathrm{mol} \mathrm{min}{ }^{-1} \mathrm{mg}^{-1}$ of protein for hypoxanthine [17]. For T. foetus HGPRT, these values are 2.2 and $2.3 \mu \mathrm{mol} \mathrm{min}^{-1} \mathrm{mg}^{-1}$ of protein for the two bases [18] while for $E$. tenella HGPRT, the specific activities are 4.9 and 6.4, respectively [19]. Thus, in general, the enzymes from the protozoan parasites exhibit lower specific activities than the human counterpart. The reason for this may be that, in some parasites, the 6-oxopurine PRTases are expressed at high levels and, therefore, their turnover rates do not have to be as high as human HGPRT.

The kinetic constants, $k_{\text {cat }}$ and $K_{\mathrm{m}}$, of recombinant $P v$ HGPRT for the naturally-occurring purine base substrates are given in Table 1. Considering catalytic efficiency, $k_{\text {cat }} / K_{\mathrm{m}}$ values for guanine and hypoxanthine are similar. PfHGXPRT favours hypoxanthine with a ratio of $k_{\text {cat }} / K_{\mathrm{m}}$ (hypoxanthine): $k_{\text {cat }} / K_{\mathrm{m}}$ (guanine) of 6 and human HGPRT prefers guanine, with a ratio of $k_{\text {cat }} / K_{\mathrm{m}}$ (hypoxanthine): $k_{\text {cat }} / K_{\mathrm{m}}$ (guanine) of 0.3 . This difference in specificity between the parasite and human enzymes may reflect the fact that, in the parasitic cell, hypoxanthine is the primary precursor for synthesis of the purine nucleoside monophosphates. PvHGPRT binds hypoxanthine with a 2 -fold greater affinity compared with guanine (compare $K_{\mathrm{m}}$ values in Table 1$)$ while for PfHGXPRT the $K_{\mathrm{m}}$ ratio is $12\left(K_{\mathrm{m}}\right.$ is $0.07 \pm 0.03 \mu \mathrm{M}$ for hypoxanthine and $0.83 \pm 0.5 \mu \mathrm{M}$ for guanine) [16]. The affinity for both purine bases is higher for the Pf enzyme compared with PvHGPRT, being 13-fold greater for hypoxanthine and 4-fold greater for guanine, suggesting differences in the mode of binding of these bases between the two enzymes. In contrast, for the human enzyme, the situation is reversed with guanine binding more tightly than hypoxanthine ( $K_{\mathrm{m}}$ for hypoxanthine is $3.4 \pm 1.0 \mu \mathrm{M}$ and for $K_{\mathrm{m}}$ for guanine is $\left.1.9 \pm 0.4 \mu \mathrm{M}\right)$ [16]. Thus, all three enzymes have different affinities for these two naturallyoccurring substrates.

A striking difference between PvHGPRT and PfHGXPRT is in their ability to use xanthine. As for human HGPRT [16], xanthine is not a substrate for $P v$ HGPRT with a calculated $k_{\text {cat }} / K_{\mathrm{m}} \leq 5 \mathrm{M}^{-1} \mathrm{~s}^{-1}$. However, xanthine is a good substrate for PfHGXPRT in terms of $k_{\text {cat }}$ $\left(3.3 \pm 0.2 \mathrm{~s}^{-1}\right)$ though it binds weakly $\left(K_{\mathrm{m}}=183 \pm 18 \mu \mathrm{M}\right)$ [16], giving $k_{\text {cat }} / K_{\mathrm{m}}=2 \times 10^{4} \mathrm{M}^{-1} \mathrm{~s}^{-1}$. It has been proposed that PfHGXPRT evolved to be able to use xanthine as this may be the purine base in highest concentration during its life cycle in the mosquito. However, the $P v$ enzyme appears not to have this requirement and can replicate without the necessity of having to use the third naturallyoccurring base. Therefore, it is possible that the xanthine activity in PfHGXPRT may have arisen due to an evolutionary accident rather than to perform a function critical to the survival of the parasite.

There is little difference in the $K_{\mathrm{m}}$ for $P$ Rib- $P P$ between the three enzymes indicating that, in the areas that bind the pyrophosphate and 5'-phosphate moieties, the structures are highly conserved. This result is confirmed by the similarity in amino acid sequence in these regions. PvHGPRT binds GMP and IMP more weakly than the $P f$ or human enzymes. For PvHGPRT, the $K_{\mathrm{i}}$ for IMP is $62 \mu \mathrm{M}$ and for GMP, this value is $26.1 \mu \mathrm{M}$. PfHGXPRT binds these compounds more tightly, with $K_{\mathrm{i}}$ values of $3.6 \pm 1 \mu \mathrm{M}$ and $10 \pm 2 \mu \mathrm{M}$, respectively [11]. The human enzyme is more similar to PfHGXPRT in this respect having much lower $K_{\mathrm{i}}$ values for IMP and GMP than $P v$ HGPRT ( $K_{\mathrm{i}}$ for IMP is $5.4 \pm 1.2 \mu \mathrm{M}$ and, for GMP, $5.8 \pm 0.2 \mu \mathrm{M}$ ) [11]. Given that $P v$ HGPRT binds hypoxanthine 2-fold more tightly than guanine, it is surprising that for the mononucleotides the situation is reversed. This suggests that the binding of the purine base is not the primary contributing factor to the $K_{\mathrm{i}}$ value for the mononucleotides. Because of the significant differences between these three enzymes in their ability to use the naturally occurring purine bases, the kinetic constants for a number of base analogs for PvHGPRT were measured (Table 1). PvHGPRT does not discriminate greatly between these bases in terms of $k_{\text {cat }}$ (Table 1 ). However, for $P v$ HGPRT, the substitution of a nitrogen atom for a carbon atom in the 8-position of the purine base resulted in a 100-300-fold increase in the $K_{\mathrm{m}}$. The replacement of the 6-oxo exocyclic group by a thio group (6-mercaptopurine and 6-thioguanine) had little effect on the $K_{\mathrm{m}}$ (Table $1 ;$ [4]) for all three enzymes, indicating that the role of the exo-cyclic group in this position is to confer specificity for the 6-oxopurine bases as against the 6-amino group required by adenine PRTase [4]. The exocyclic groups in this position form a hydrogen bond with the $\varepsilon$-amino group of the invariant lysine residue that is found in all the known 6-oxopurine PRTases structures (K177 in PvHGPRT). 6-Mercaptopurine and 6thioguanine are good substrates for PvHGPRT in terms of catalytic efficiency $\left(k_{\text {cat }} / K_{\mathrm{m}}\right)$ (Table 1$)$. For PfHGXPRT, 6-mercaptopurine is by far the preferred substrate, having a $k_{\text {cat }} / K_{\mathrm{m}}$ of $20 \mu \mathrm{M}^{-1} \mathrm{~s}^{-1}$ compared with $1.2 \mu \mathrm{M}^{-1} \mathrm{~s}^{-1}$ for 6-thioguanine [4]. This is consistent with the fact that PfHGXPRT binds hypoxanthine with 13-fold higher affinity than the $P v$ enzyme. Substitutions in the imidazole portion of the purine base have a marked effect on the selectivity for $P v$ HGPRT. Such substitutions virtually abolish binding. A similar result is observed for the human enzyme. Thus, 8 -azaguanine is a very weak substrate for $P v$ HGPRT with a $k_{\text {cat }} / K_{\mathrm{m}}$ of $0.004 \mu \mathrm{M}^{-1} \mathrm{~s}^{-1}$, similar to that found for the human HGPRT $\left(0.005 \mu \mathrm{M}^{-1} \mathrm{~s}^{-1}\right)$ [4]. In comparison, this base is a good substrate for PfHGXPRT, having a $k_{\text {cat }}$ of $4.9 \pm 0.02 \mathrm{~s}^{-1}$ and a $K_{\mathrm{m}}$ of $12.6 \pm 0.2 \mu \mathrm{M}\left(k_{\text {cat }} / K_{\mathrm{m}}\right.$ of $\left.0.4 \mu \mathrm{M}^{-1} \mathrm{~s}^{-1}\right)$ [4]. For 8 -azahypoxanthine, $k_{\text {cat }} / K_{\mathrm{m}}$ is identical to that found for 8 -azaguanine using PvHGPRT though the $k_{\text {cat }}$ and $K_{\mathrm{m}}$ values are 
Table 2

Inhibition of $P v$ HGPRT by acyclic nucleoside phosphonates.

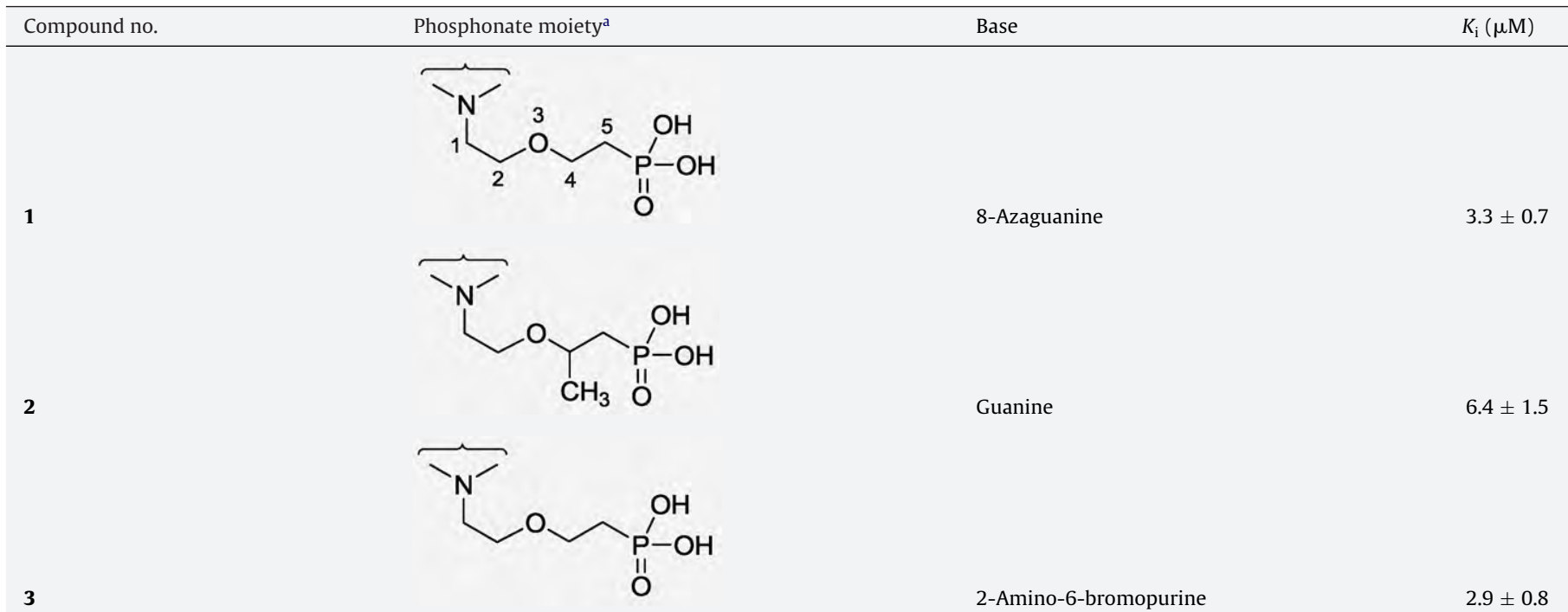

a The acyclic chain is attached to the $\mathrm{N}^{9}$-position of the purine base. Synthesis of compound 1: 9-[2-(phosphonoethoxy)ethyl]-8-azaguanine was prepared analogously

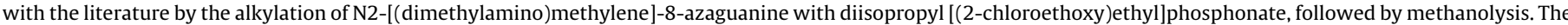

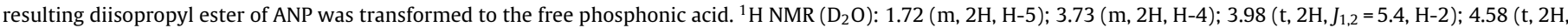

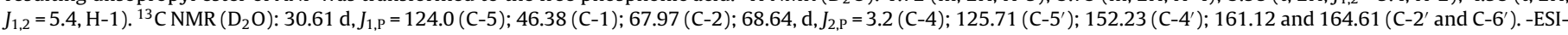

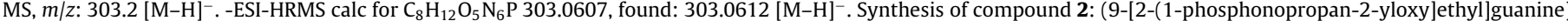

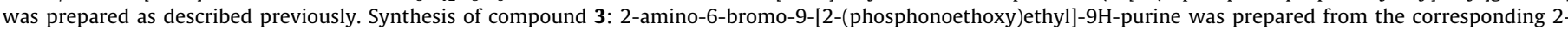

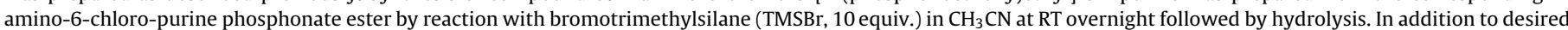

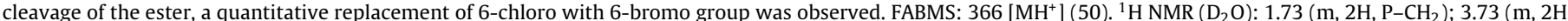

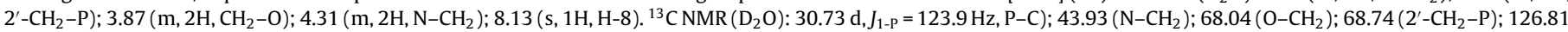
(C-5); 142.86 (C-6); 145.33 (C-8); 152.61 (C-4); 159.76 (C-2). For $\mathrm{C}_{9} \mathrm{H}_{15} \mathrm{BrN}_{5} \mathrm{O}_{5} \mathrm{P}$. $\mathrm{H}_{2} \mathrm{O}$ (366.11) Calculated: C, 28.14; H, 3.94; N, 18.23. Found: C, 28.27; H, 4.01; N, 18.01.

both doubled. These two values are also doubled for PfHGXPRT and, although the $k_{\text {cat }} / K_{\mathrm{m}}$ values are the same for both substrates, the parasite enzymes bind the hypoxanthine analog more weakly than the guanine analog. For the human enzyme, 8-azahypoxanthine is such a weak substrate that no rate could be detected and the calculated $k_{\text {cat }} / K_{\mathrm{m}}$ is $\leq 1.1 \times 10^{3} \mathrm{M}^{-1} \mathrm{~s}^{-1}$ [4]. For PvHGPRT, allopurinol (8-aza-7-deazahypoxanthine) is a very weak substrate with $k_{\text {cat }} / K_{\mathrm{m}}$ being $1.7 \times 10^{3} \mathrm{M}^{-1} \mathrm{~s}^{-1}$. For allopurinol, the $k_{\text {cat }} / K_{\mathrm{m}}$ value for PfHGXPRT is $6 \times 10^{4} \mathrm{M}^{-1} \mathrm{~s}^{-1}$ while for human HGPRT, this value is similar to that for PvHGPRT $\left(3 \times 10^{3} \mathrm{M}^{-1} \mathrm{~s}^{-1}\right)$ [4]. Overall, these results show that the $P v$ and human enzymes are far less tolerant of atomic substitutions in the imidazole ring than is PfHGXPRT. Purine base analogs inhibit the growth of $P f$ in cell culture thus making them potential drug leads [4]. Furthermore, 6-mercaptopurine and 8 -azaguanine have been found to arrest parasitemia in mice infected with the malarial strain of Plasmodium berghei with $\mathrm{IC}_{50}$ values of $47 \mu \mathrm{M}$ and $32 \mu \mathrm{M}$, respectively (Guddat et al., unpublished). P. vivax is unable to be cultured and the only in vivo testing available is in monkeys or related mammals [20].

Because ANPs have previously been shown to be good inhibitors of PfHGPRT [10], three of these compounds were investigated as potential inhibitors of PvHGPRT (Table 2). The structures of these ANPs (Table 2) differ in the purine base and the linker between the base and the phosphonate group. ANPs arrest the growth of Pf in cell culture [10]. These compounds contain a phosphonate group that binds in the 5'-phosphate binding pocket in human HGPRT [10]. This group is one of the anchors that hold the ANPs in position. There are three separate entities that contribute to the affinity of the ANPs for the active site: the purine base, the linker between the base and the phosphonate group and the phosphonate group itself. When modifications to two or more of these entities are made the overall effect can either be synergistic or the changes may negate each other. This is demonstrated by the fact that, although 8 -azaguanine is a very poor substrate for PvHGPRT, compound $\mathbf{1}$ is a good inhibitor of the enzyme. The tight binding is, therefore, due primarily to the phosphonate moiety and the linker. 2-Amino6-bromopurine with the same phosphonate moiety (compound 3) is also a good inhibitor. Both these compounds inhibit PfHGXPRT with $\mathrm{K}_{\mathrm{i}}$ values of $0.2 \mu \mathrm{M}$ (compound 1) and $1.3 \mu \mathrm{M}$ (compound $\mathbf{3}$ ). Compound $\mathbf{2}$ is still a good inhibitor of PvHGPXRT therefore there must be room in the active site to accommodate the methyl group in the 4-position in the linker. However, this compound binds more tightly to the human enzyme with a $\mathrm{K}_{\mathrm{i}}$ value 10 -fold lower than for the parasite enzymes [21]. These results, along with the $k_{\text {cat }}$ data for the substrates further highlight that structural differences in the active sites of these three enzymes must exist. An ANP with a $K_{\mathrm{i}}$ value of $8 \mu \mathrm{M}$ exhibited an $\mathrm{IC}_{50}$ value of $1 \mu \mathrm{M}$ against $P f$ cells grown in culture [11]. It is expected that good inhibitors of $P v$ HGPRT described in Table 2 will inhibit the growth of $P$. vivax. The potential of these three ANP compounds for anti-malarial therapy is further demonstrated by their low cytotoxicity in human cell cultures, which suggests that they have minimal, if any, inhibitory effect on cellular enzymes (including human HGPRT). In human A549 and U251 cell lines, their 50\% cytostatic concentrations were $260 \mu \mathrm{M}$ (compound 1), and $>600 \mu \mathrm{M}$ (compounds 2 and 3 ).

The two Plasmodium 6-oxopurine PRTases show 77\% identity in their primary sequences. Their identities are much lower when compared to human HGPRT. For PfHGXPRT this value is $45 \%$ while, for PvHGPRT, it is $39 \%$. However, as expected from the kinetic data, the residues that line the surface of the purine, pyrophosphate and 5 -phosphate binding sites are conserved between the two parasite enzymes. The regions of largest difference in the primary sequence between the two parasite enzymes are at the $\mathrm{N}$-terminus (residues 14-20), the C-terminus (residues 223-232), and residues 98-107 and $122-125$, which are regions near a large mobile loop that covers the active site during catalysis [9]. Based on the known crystal structures of bacterial and human PRTases, these regions themselves are generally highly flexible [13-15]. Thus, the difference in the cat- 
alytic and physical properties between the two parasite enzymes is most likely attributed to differences in flexibility conferred by amino acid residues in these regions.

$P v$ HGPRT differs from both PfHGXPRT and human HGPRT in its catalytic properties. These differences are reflected in the $k_{\text {cat }}$ and $K_{\mathrm{m}}$ values for the naturally-occurring purine bases and also for purine base analogs. PvHGPRT appears to require the presence of magnesium to maintain its active site conformation as do the two E. coli enzymes, XGPRT and HPRT. Neither human HGPRT nor $P f H G X P R T$ has this requirement. ANPs are selective and potent inhibitors of PfHGXPRT and are effective in arresting the growth of $P f$ in cell culture. The ANPs reported here are good inhibitors of $P v$ HGPRT with $K_{\mathrm{i}}$ values as low as $3 \mu \mathrm{M}$. Based on these data, ANPs that inhibit PvHGPRT will generally be good inhibitors of PfHGXPRT though there will be significant differences in their $K_{\mathrm{i}}$ values based on the structures. Thus, such compounds form a platform for the design of more potent inhibitors and for testing of their in vivo activity.

\section{Acknowledgements}

We wish to thank Wim van Dam for excellent technical assistance in the cytotoxicity studies. This work is supported by grant number 569703 from the National Health and Medical Research Council, Australia. The synthesis of ANPs was performed as a part of research project AVOZ40550506 of the Institute of Organic Chemistry and Biochemistry and was supported by Centre for New Antivirals and Antineoplastics (1M0508).

\section{References}

[1] Mueller I, Galinski MR, Baird JK, et al. Key gaps in the knowledge of Plasmodium vivax, a neglected human malaria parasite. Lancet Infect Dis 2009;9: 555-66.

[2] Price RN, Tjitra E, Guerra CA, Yeung S, White NJ, Anstey NM. Vivax malaria: neglected and not benign. Am J Trop Med Hyg 2007;77(6 Suppl):79-87.

[3] Ting L-M, Shi W, Lewandowicz A, et al. Targeting a novel Plasmodium recycling pathway with specific immucillins. J Biol Chem 2005;280:9547-54.

[4] Keough DT, Skinner-Adams T, Jones MK, et al. Lead compounds for antimalarial chemotherapy: purine base analogs discriminate between human and $P$. falciparum 6-oxopurine phosphoribosyltransferases. J Med Chem 2006;49:7479-86.
[5] Nelson JA, Carpenter JW, Rose LM, Adamson DJ. Mechanisms of action of 6-thioguanine, 6-mercaptopurine, and 8-azaguanine. Cancer Res 1975;35:2872-8.

[6] Berens RL, Krug EC, Marr JJ. Purine and pyrimidine metabolism. In: Marr JJ, Muller M, editors. Biochemistry and molecular biology of parasites. New York: Academic Press; 1995. pp. 89-117(25).

[7] Parker MD, Hyde RJ, Yao SYM, et al. Identification of a nucleoside/nucleobase transporter from Plasmodium falciparum, a novel target for anti-malarial chemotherapy. Biochem J 2000;349:67-75.

[8] Wallace LJM, Candlish D, De Koning HP. Different substrate recognition motifs of human and trypanosome nucleobase transporters. J Biol Chem 2002;277:26149-56.

[9] Li CM, Tyler PC, Furneaux RH, et al. Transition state analogs as inhibitors of human and malarial hypoxanthine-guanine phosphoribosyltransferases. Nat Struct Biol 1999;6:582-7.

[10] Keough DT, Hocková D, Holý A, et al. Inhibition of hypoxanthine-guanine phosphoribosyltransferase by acyclic nucleoside phosphonates: a new class of antimalarial therapeutics. J Med Chem 2009;52:4391-9.

[11] De Clercq E, Andrei G, Balzarini J, et al. Antitumor potential of acyclic nucleoside phosphonates. Nucleos Nucleot 1999;18:759-71.

[12] Carlton JM, Adams JH, Silva JC, et al. Comparative genomics of the neglected human malaria parasite Plasmodium vivax. Nature 2008;455: 757-63.

[13] Vos S, de Jersey J, Martin JL. Crystal structure of Escherichia coli xanthine phosphoribosyltransferase. Biochemistry 1997;36:125-34.

[14] Guddat LW, Vos S, Martin JL, Keough DT, de Jersey J. Crystal structures of free, IMP-, and GMP-bound Escherichia coli hypoxanthine phosphoribosyltransferase. Protein Sci 2002;11:1626-38.

[15] Keough DT, Brereton IM, de Jersey J, Guddat LW. The crystal structure of free human hypoxanthine-guanine phosphoribosyltransferase reveals extensive conformational plasticity throughout the catalytic cycle. J Mol Biol 2005;351:170-81.

[16] Keough DT, Ng AL, Winzor DJ, Emmerson BT, de Jersey J. Purification and characterization of Plasmodium falciparum hypoxanthine-guanine-xanthine phosphoribosyltransferase and comparison with the human enzyme. Mol Biochem Parasitol 1999;98:29-41.

[17] Yuan L, Craig III SP, McKerrow JH, Wang CC. Steady-state kinetics of Schistosomal hypoxanthine-guanine phosphoribosyltransferase. Biochemistry 1992;31:806-10.

[18] Beck JT, Wang CC. The hypoxanthine-guanine-xanthine phosphoribosyltransferase from Tritrichomonas foetus has unique properties. Mol Biochem Parasitol 1993;60:187-94.

[19] Wang CC, Simashkevich PM. Purine metabolism in the protozoan parasite Eimeria tenella. Proc Natl Acad Sci USA 1981;78:6618-22.

[20] Sherman W. Marine parasite biology pathogenesis and protection. Washington DC: ASM Press; 1998.

[21] Hocková D, Holý A, Masojídková M, Keough DT, Jersey J, Guddat LW. Synthesis of branched 9-[2-(2-phosphonoethoxy)ethyl]purines as a new class of acyclic nucleoside phosphonates which inhibit Plasmodium falciparum hypoxanthine-guanine-xanthine phosphoribosyltransferase. Bioorg Med Chem 2009;17:6218-32. 